\title{
INSETOS E ÁCAROS ASSOCIADOS AO AMARELINHO NO MUNICÍPIO DE LONDRINA, PARANÁ, COM POTENCIAL PARA SEU CONTROLE BIOLÓGICO
}

\section{INSECTS AND MITES ASSOCIATED WITH YELLOW-BELLS IN THE COUNTY OF LONDRINA, PARANÁ, BRAZIL, WITH POTENTIAL TO ITS BIOLOGICAL CONTROL}

\author{
Homero Christoval SIMÕES ${ }^{1}$ \\ Ayres de Oliveira MENEZES JR ${ }^{2}$ \\ Fernanda Maura Sassiotti DALBERTO ${ }^{3}$
}

\begin{abstract}
RESUMO
O trabalho objetivou conhecer a fauna de insetos e ácaros associados com potencial para controlar Tecoma stans, e estudar sua flutuação populacional no campo. As coletas foram realizadas no município de Londrina-PR, entre novembro/2002 a outubro/2003. As amostragens foram quinzenais, capturando-se os artrópodes em dez plantas, através de inspeção visual e armadilha adesiva amarela. Diferentes insetos foram coletados, destacando-se aqueles pertencentes a ordem Hemiptera com $48,9 \%$ dos indivíduos capturados. As espécies Eulepte sp. (Lepidoptera: Pyralidae) e Tetranychus Iudeni (Acari: Tetranychidae) destacaram-se pelos danos causados, apresentando respectivamente 45,3 e $15,4 \%$ de freqüência na análise visual, sendo consideradas espécies acessórias. Observou-se pico na população de lagartas de Eulepte sp. no fim do mês de março, com média de 7,6 lagartas por planta. O número de adultos de T. ludeni por planta foi variável ao longo do período estudado, chegando a atingir no fim do mês de janeiro/03 a média de 35 adultos por planta. Diversos parasitóides de Eulepte sp. foram obtidos de lagartas coletadas no campo, sendo as espécies mais numerosas pertencentes à família Braconidae (Hymenoptera). A flutuação populacional de Eulepte sp. correlacionou-se positivamente com a temperatura, não correlacionando-se porém com a precipitação. As oscilações populacionais de T. ludeni não tiveram correlação com as oscilações nas variáveis climáticas estudadas.
\end{abstract}

Palavras-chave: Levantamento faunístico; Tecoma stans; Tetranychus ludeni; planta invasora.

\begin{abstract}
The objective of this work was to identify the insects and mites associated to Tecoma stans with the greatest potential for its biological control, and to study their population dynamics in the field. Collections were carried out in the county of Londrina,Paraná, Brazil, from November 2002 to October 2003. Sampling occurred quarterly, using 10 plants, and adopting the visual inspection and the yellow sticky trap to capture the insects. Several orders were caught, especially the Hemiptera, with $48,9 \%$ of the total specimens caught. Eulepte sp. (Lepidoptera: Pyralidae) and Tetranychus ludeni (Acari: Tetranychidae) were the most destructive species, showing $45,3 \%$ and $15,4 \%$ of frequency in the inspection analysis, being considered accessory species. Eulepte sp. larval population density peak was observed in the end of March, with an average of 7,6 larvae per plant. The number of $T$. Iudeni adults showed great variations throughout the period under study, reaching an average of 35 adults per plant in the end of January. Several Eulepte parasites were obtained from larvae collected in the field and the two more numerous species belonging to the Braconidae family (Hymenoptera). Eulepte sp. larval population fluctuation correlated positively with the temperature but not with precipitation. The population of $T$. ludeni showed no significant correlation with the weather conditons studied.
\end{abstract}

Key words: faunistic survey; Stenolobium stans; Tetranychus ludeni; weed.

\footnotetext{
${ }^{1}$ Mestre em Agronomia, ex-aluno Universidade Estadual de Londrina (UEL). Rua Martin Luther King, 132, Jardim Lago Parque, CEP 86015-300 - Londrina, Paraná, Brasil. E-mail: hcsimoes@yahoo.com.br. Autor para correspondência.

${ }_{2}$ Professor Dr. do Departamento de Agronomia, Universidade Estadual de Londrina (UEL), Londrina, Paraná, Brasil. E-mail: ayres@uel.br.

${ }^{3}$ Mestre em Agronomia, ex-aluna Universidade Estadual de Londrina (UEL), Londrina, Paraná, Brasil. E-mail: fernandadalberto@yahoo.com.br.
} 
SIMÕES, H.C. et al. Insetos e ácaros associados ao amarelinho...

\section{INTRODUÇÃO}

A família Bignoniaceae é composta por plantas lenhosas, arbustivas, arbóreas ou cipós, as quais são essencialmente tropicais compreendendo 120 gêneros (Joly, 1976) e cerca de 750 espécies (Schultz, 1963). Os gêneros Stenolobium e Tecoma correspondem aqueles de maior destaque na flora brasileira.

A espécie Tecoma stans (L.) Kunth (=Stenolobium stans), é originária do México e sul dos Estados Unidos (Mello, 1952), sendo vulgarmente conhecida como amarelinho, ipê de jardim, guarã-guarã, ipê-mirim e caroba amarela. De acordo com Morton (1981) há relatos de pelo menos 80 denominações diferentes, sendo no Paraná mais conhecida como amarelinho. $T$. stans é considerada planta invasora em vários países (Holm et al., 1979) e, recentemente, também no Brasil (Kranz \& Passini, 1997), principalmente nos estados da região sul do país. Trata-se de uma espécie introduzida no Brasil como elemento de ornamentação em praças e jardins e, devido ao seu rápido e intenso poder de rebrote, tanto de origem caulinar como radicular, através de gemas caulinares e raízes gemíferas (Renó, 2002) e de dispersão, através da produção de sementes aladas, tornou-se espontânea e causadora de sérios problemas, principalmente, em pastagens. No Estado do Paraná, foi encontrada como invasora em 50 mil ha de pastagens de 85 municípios, dos quais, dez mil hectares tornaram-se praticamente improdutivos (Kranz \& Passini, 1997). Essa versatilidade na produção de brotos e sementes faz de $T$. stans uma espécie altamente adaptada e agressiva na infestação e reinfestação de áreas após a tentativa de controle por práticas químicas, físicas e/ou mecânicas.

Pouco se conhece, ainda, sobre os métodos de controle dessa invasora no Brasil. Passini \& Kranz, (1997) estudaram o controle químico de $T$. stans, testando a eficiência da formulação comercial de 2,4-D + picloram e tebuthiuron, em várias concentrações e doses. Os resultados demonstraram que apenas o tebuthiuron foi eficiente, porém, despendendo alto custo e tempo para a ação efetiva do produto, além de não ser registrado pelo Ministério da Agricultura Pecuária e Abastecimento (MAPA) para o controle do amarelinho no Brasil.

Em relação aos agentes biológicos com potencial para o controle da planta, existem poucas informações na bibliografia nacional. No âmbito internacional, Lee et al. (2000) estudaram a diversidade e abundância de insetos e ácaros associados ao amarelinho, porém, sem o objetivo de identificar uma espécie que possa ser utilizada para seu controle. Neste trabalho, os autores verificaram a presença de 44 espécies de diferentes ordens associadas ao amarelinho.

Com o propósito de gerar conhecimentos básicos para um plano de manejo de populações de $T$. stans no campo, objetivou-se conhecer os insetos e ácaros com potencial para o controle do amarelinho, estudando as variações populacionais relacionadas aos principais fatores climáticos (precipitação; temperaturas máxima, média e mínima).

\section{MATERIAL E MÉTODOS}

As coletas foram realizadas em área do município de Londrina, Paraná (latitude $23^{\circ} 22^{\prime} \mathrm{S}$, longitude $51^{\circ} 05^{\prime} \mathrm{W}$ e altitude $600 \mathrm{~m}$ ), com cerca de $5000 \mathrm{~m}^{2}$, inserida em uma área de pastagem de 10 ha totalmente infestada por $T$. stans (densidade média de 3,4 plantas $\mathrm{m}^{-2}$ ), com declividade de $15 \%$ e apresentando goiabeira (Psidium guajava L.) e alecrim-do-campo (Baccharis dracunculifolia DC.) como espécies de plantas de ocorrência conjunta com $T$. stans. A área se apresentava homogênea com plantas de aproximadamente 5 anos de idade, não provenientes de rebrotes, e com alturas em torno de $2,0 \mathrm{~m}$.

A amostragem consistiu na inspeção manual de flores, frutos, ramos e folhas, e por observação direta na planta (Southwood, 1966), com o auxílio de lupa, sendo capturadas e registradas todas as espécies de insetos e ácaros encontradas. Procurou-se abranger toda a planta, não priorizando nenhuma estrutura. A inspeção visual foi efetuada em 10 plantas ao acaso, quinzenalmente, analisando-se plantas diferentes em cada amostragem, mas com aproximadamente a mesma idade e porte.

Para coleta dos artrópodes foram utilizados equipamentos como: rede entomológica, frascos de diversos tamanhos, câmara letal e gerbox. Materiais vivos coletados em campo, como ovos, larvas e pupas foram levados ao Laboratório de Entomologia da Universidade Estadual de Londrina - UEL, Londrina, Paraná, sendo criado em condições controladas de temperatura a $25^{\circ} \mathrm{C}$, com a finalidade de observar comportamento e parasitismo, bem como obter adultos para identificação.

Foram utilizadas, também, armadilhas adesivas amarelas, confeccionadas com copos de plástico rígido de $300 \mathrm{~cm}^{3}$, pintados com tinta automotiva de coloração amarelo-ouro, e revestidos com cola própria para captura de insetos (Gel-Trap, Jteaton ${ }^{\circledR}$ ). Distribuiu-se uma armadilha por planta, em 10 plantas de $T$. stans, distanciadas entre si cerca de $20 \mathrm{~m}$. As armadilhas foram instaladas na parte interna da planta, em meio às folhagens, a uma altura aproximada de $1,5 \mathrm{~m}$ do solo. A troca das armadilhas ocorreu quinzenalmente.

Os artrópodes coletados nas armadilhas amarelas foram descolados com o uso de pincel e vaselina líquida, transferidos para placas de Petri com registro da data de coleta. O mesmo procedimento foi adotado para o material coletado pela inspeção visual. Em seguida todo material foi armazenado em freezer, a $5{ }^{\circ} \mathrm{C}$ até posterior montagem. Exemplares dos espécimens coletados foram montados em alfinetes entomológicos e mantidos a seco, ou acondicionados em Eppendorfes $\left(1,5 \mathrm{~cm}^{3}\right)$ com álcool na concentração de $70 \%$.

Exemplares representativos de cada 
SIMÕES, H.C. et al. Insetos e ácaros associados ao amarelinho...

espécie coletada foram depositados em coleção entomológica mantida no Laboratório de Entomologia da Universidade Estadual de Londrina - UEL, constituindo um mostruário de referência. A identificação taxonômica, ao nível de família, foi efetuada com auxílio de literatura especializada (Borror \& Delong, 1969; Marucci et al., 1999; Dutra \& Machado, 2001) ou mediante o envio de espécimes a especialistas.

Procedeu-se a quantificação apenas das espécies que foram encontradas se alimentando ou causando alguma injúria à planta, as quais foram classificadas como possíveis agentes de controle, e a determinação da freqüência desses artrópodes, através da porcentagem de indivíduos de uma dada espécie em relação ao total de indivíduos capturados com o mesmo método de amostragem. Calculou-se também a constância destas espécies, empregando-se a seguinte fórmula (Silveira Neto et al., 1976): $C(\%)=P / N .100$ - onde: $C=$ Constância das espécies, expressa em porcentagem; $\mathrm{P}=$ Número de coletas contendo a espécie; $N=$ Número de coletas realizadas.

Segundo Silveira Neto et al. (1976), a constância é caracterizada em: espécies constantes: aquelas presentes em mais de $50 \%$ das coletas; espécies acessórias: aquelas presentes de
$25 \%$ a $50 \%$ das coletas; espécies acidentais: aquelas presentes em menos de $25 \%$ das coletas.

O número de indivíduos coletados das espécies potenciais agentes de controle foi correlacionado com os registros de temperatura e precipitação através do teste de correlação de Pearson, considerando o nível de significância de $5 \%$ (SAS, 1998).

Os registros diários de temperatura $\left({ }^{\circ} \mathrm{C}\right)$ máxima, mínima, média e precipitação $(\mathrm{mm})$, no período correspondente ao trabalho, foram obtidos pela estação meteorológica do Instituto Agronômico do Paraná, IAPAR, localizado no município de Londrina, distante aproximadamente $8 \mathrm{~km}$ do local de avaliação.

\section{RESULTADOS E DISCUSSÃO}

Diferentes grupos de insetos e uma espécie de ácaro foram encontrados em plantas de $T$. stans no município de Londrina, PR. Entre as principais ordens de insetos as predominantes foram, respectivamente, Hemiptera-Auchenorryncha, com $45,2 \%$ do total de espécimes coletados; Diptera $(18 \%)$; Coleoptera (7\%); Hymenoptera (6,4\%); Lepidoptera $(5,1 \%)$ e Hemiptera-Sternorryncha $(3,7 \%)$ (Figura 1). A ordem Acari apresentou nível de freqüência de $14,2 \%$.

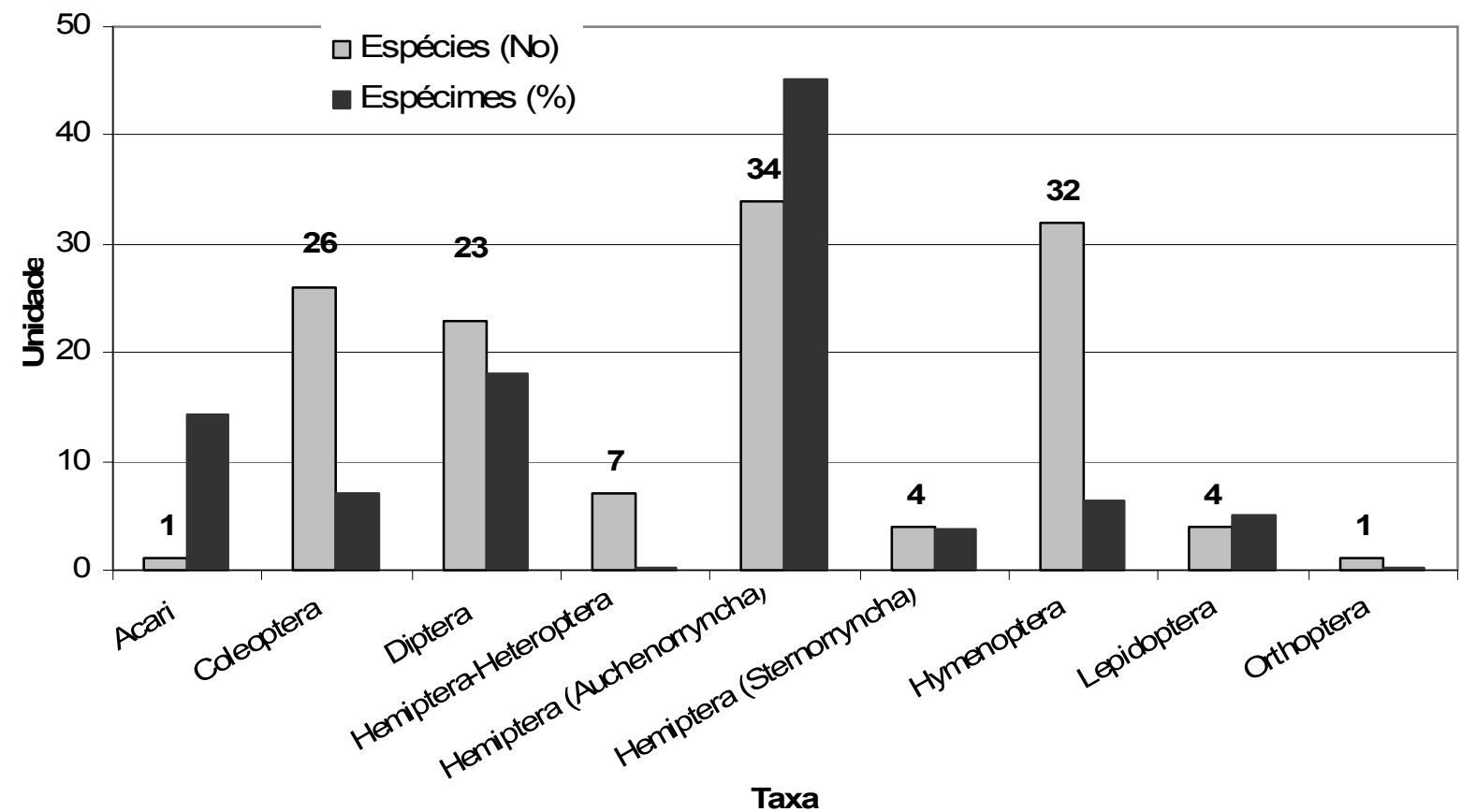

FIGURA 1 - Diversidade de espécies e \% de espécimes de insetos e ácaros coletados, por armadilha adesiva e inspeção visual, em plantas de T. stans, no período de novembro/ 2002 a outubro/ 2003. LondrinaPR.

As cigarrinhas (Hemiptera: Auchenorryncha) corresponderam ao grupo de insetos mais abundante em plantas de $T$. stans, especialmente aquelas da família Cicadellidae. A espécie Scopogonalia subolivacea (Stal) foi a mais freqüente nos dois métodos de amostragem, com
$16,6 \%$ do total de indivíduos capturados. Em pomares cítricos, doze espécies de cigarrinhas pertencentes a família Cicadellidae foram registradas como transmissoras da bactéria Xylella fastidiosa (Wells et al.), causadora da CVC (Clorose Variegada dos Citros) (Yamamoto \& Gravena, 
SIMÕES, H.C. et al. Insetos e ácaros associados ao amarelinho...

2000). No presente estudo foram encontradas seis dessas espécies se alimentando em ramos novos e tenros de $T$. stans (Tabela 1), sendo preciso pesquisar se esta planta pode servir, também, de hospedeiro para a mesma bactéria. Portanto, os resultados obtidos nessa pesquisa conjecturam outro aspecto prejudicial à invasora, ou seja, como fonte de inóculo do patógeno (caso a bactéria se desenvolva em seus vasos), ou mesmo como alimento para a manutenção e desenvolvimento das espécies de cicadelídeos transmissores.

TABELA 1 - Índice de freqüência e constância de insetos (incluindo cigarrinhas transmissoras da CVC) e ácaro fitófagos, associados a T. stans, no período de novembro/ 2002 a outubro/ 2003. Londrina-PR.

\begin{tabular}{|c|c|c|}
\hline Taxa & $\begin{array}{c}\text { Freqüência } \\
(\%)\end{array}$ & Constância $(\%)^{1}$ \\
\hline \multicolumn{3}{|l|}{ Acari $^{2}$} \\
\hline Tetranychus ludeni Zacher (Tetranychidae) & 45,30 & $25,0 \mathrm{Y}$ \\
\hline \multicolumn{3}{|l|}{ Homoptera } \\
\hline Acrogonia citrina (Cicadellidae) & 2,80 & $63,6 \times$ \\
\hline Bucephalogonia xanthophis (Cicadellidae) & 0,22 & $18,2 \mathrm{Z}$ \\
\hline Dilobopterus costalimai (Cicadellidae) & 0,48 & $31,8 Y$ \\
\hline Macugonalia leucomelas (Cicadellidae) & 2,40 & $59,1 X$ \\
\hline Oncometopia fascialis (Cicadellidae) & 4,10 & $81,8 X$ \\
\hline Parathona gratiosa (Cicadellidae) & 0,66 & $31,8 \mathrm{Y}$ \\
\hline \multicolumn{3}{|l|}{ Lepidoptera $^{2}$} \\
\hline Eulepte sp. (Pyralidae) & 15,40 & $45,9 \mathrm{Y}$ \\
\hline Morfo - Espécie 139 (Sphyngidae) & 0,53 & $5,0 \mathrm{Z}$ \\
\hline Thalesa citrina (Arctiidae) & 0,26 & $2,7 \mathrm{Z}$ \\
\hline Morfo - Espécie 142 (Tortricidae) & 0,22 & $1,8 \mathrm{Z}$ \\
\hline
\end{tabular}

${ }^{1} \mathrm{X}=$ Espécie constante; $\mathrm{Y}=$ Espécie acessória; $\mathrm{Z}=$ Espécie acidental.

2 Índices calculados com base nos dados de inspeção visual.

$\mathrm{Da}$ ordem Hemiptera-Sternorryncha, foram encontradas duas espécies de afídeos (Aphidiinae), Aphis gossypii (Glover) e Aphis spiraecola (Patch) com níveis de freqüência de $1,46 \%$ e $1,25 \%$, respectivamente. Esses insetos foram encontrados geralmente, no ápice das plantas em ramos jovens ou nos ramos floríferos. Apenas uma espécie de predador desses pulgões, a joaninha Cycloneda sanguinea L. (Coleoptera: Coccinellidae), foi capturada. De acordo com Silva et al. (1968), esses afídeos são associados ao algodoeiro e batata, dentre outros hospedeiros. Na Colômbia, Lee et al. (2000) encontraram em $T$. stans, além de $A$. gossypii, os pulgões Macrosiphum euphorbiae (Thomas) e Myzus persicae (Sulzer), bem como alguns predadores, como o percevejo Orius sp., e parasitóides, como a vespinha Aphidius sp.

Vários coleópteros da família

Chrysomelidae e um da família Curculionidae foram coletados nos dois métodos de amostragem. De acordo com Julien \& Griffiths (1999) essas famílias são importantes no controle biológico de plantas. Contudo, esses insetos estavam apenas se refugiando em $T$. stans, pois não foram observados se alimentando ou causando danos à planta.
Possivelmente, essa alta diversidade de coleópteros pode estar relacionada à cor amarela das armadilhas que favorece a captura de vários insetos. Isso também ocorreu em levantamento de insetos pragas de batata-doce, Ipomoea batatas (Lam), onde a espécie Astylus variegatus Germ. (Coleoptera: Dasytidae) apresentou os maiores níveis de freqüência, embora não se alimentasse da planta em questão (Gonçalves, 1997). Lee et al. (2000) encontraram, apenas, uma espécie de crisomelídeo (Epitrix sp.) associado a T. stans, sendo coletado somente em alguns meses do ano, onde se apresentou pouco abundante.

Uma grande diversidade de espécies e quantidade de espécimes de dípteros foram coletados nas armadilhas, porém, não apresentaram importância para o controle biológico de $T$. stans, pois não foram encontradas se alimentando ou causando alguma injúria à planta.

Apenas quatro espécies de Lepidoptera foram observadas com lagartas se alimentando de folhas de T. stans (Tabela 1). Eram elas Eulepte sp. (Pyralidae), Thalesa citrina (Sepp) (Arctiidae), uma espécie da família Sphyngidae e uma da família Tortricidae. Devido aos altos índices de freqüência 
$(15,4 \%)$ e constância $(45,9 \%$, considerada acessória) nas coletas por inspeção visual, e dos danos causados à planta, a espécie de lagarta de hábito enrolador de folhas (Eulepte sp.) destaca-se como um possível agente de controle biológico de $T$. stans (Tabela 1). Lee et al. (2000) encontraram duas espécies de tortricídeos e uma de noctuídeo, porém, nenhum piralídeo foi citado. Na Venezuela Eulepte gastralis (GN.) é citada como uma espécie praga em viveiros de Tabebuia rosea (Bertol) DC. (Bignoniaceae), planta conhecida popularmente como Ipê rosa (Hernandez \& Briceño, 1999). No entanto, deve se tratar de espécie distinta da encontrada em $T$. stans, pois os autores descrevem algumas características morfológicas diferentes das do inseto encontrado no presente estudo.

Analisando a flutuação populacional durante o período de coleta, observa-se um incremento na população da lagarta Eulepte sp. a partir do início do mês de março, estendendo-se até o fim de maio, e pico populacional no fim de março, com média de 76 lagartas por amostragem, ou 7,6 lagartas por planta (Figura 2). No mês de junho, houve uma queda brusca na população de Eulepte sp., não tendo sido observadas lagartas a partir de agosto, até o fim das amostragens, em outubro (Figura 2).

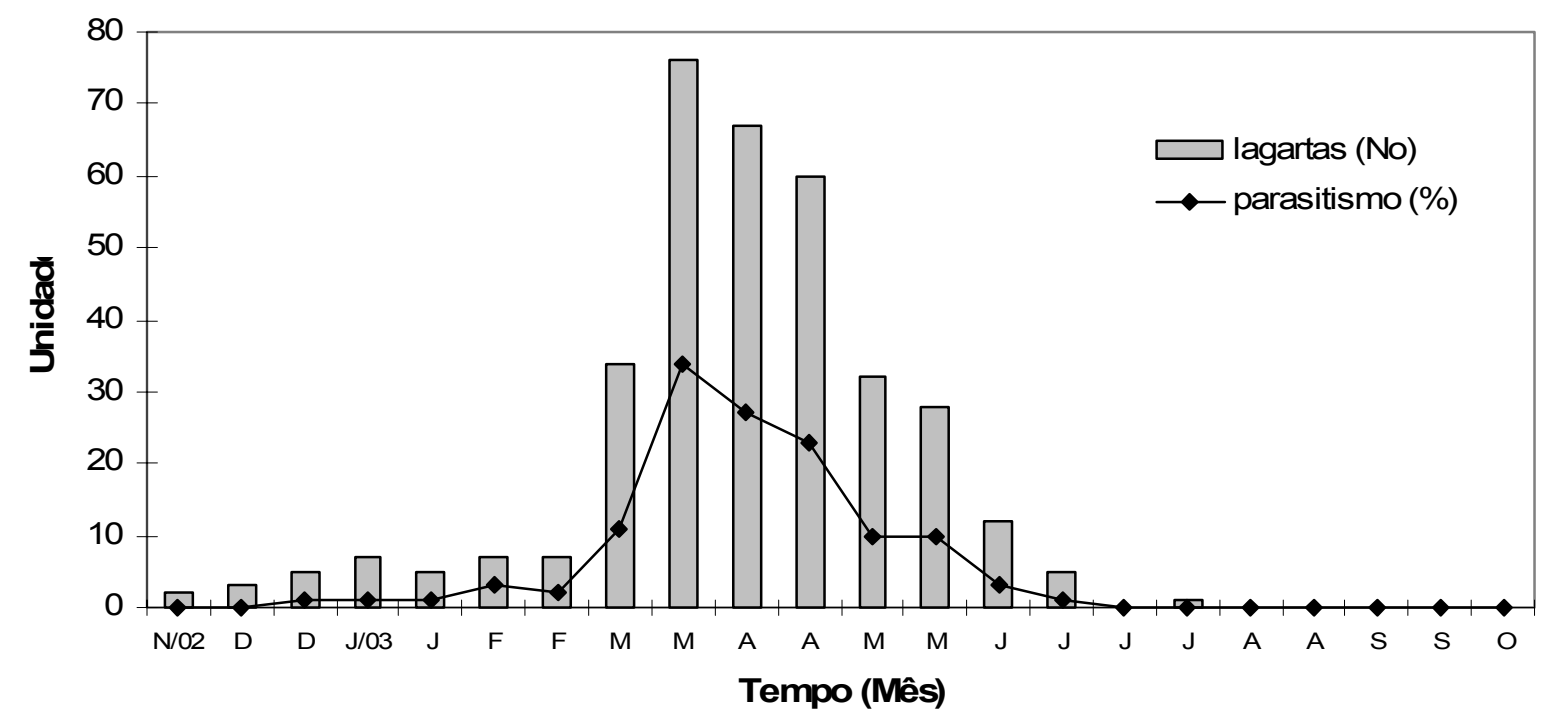

FIGURA 2 - Flutuação populacional e porcentagem de parasitismo de lagartas de Eulepte sp. (Lep., Pyralidae), coletadas quinzenalmente pelo método de inspeção visual, em $T$. stans, no período de novembro/ 2002 a outubro/ 2003. Londrina-PR.

Dentre os himenópteros, foram encontradas formigas do gênero Cephalotes (Formicidae) e oito espécies de parasitóides pertencentes à família Ichneumonidae. Essa diversidade de parasitóides da família Ichneumonidae concorda com o relato de Lee et al. (2000), onde, com o auxílio da armadilha Malaise, essa família foi coletada em maior número.

Entre os ácaros, apenas Tetranychus Iudeni Zacher (Acari: Tetranychidae) foi encontrado em plantas de $T$. stans. Esse artrópode foi geralmente encontrado na parte inferior da folha, causando clorose seguida de necrose, o que concorda com o relato de Jeppson et al. (1975). Esse autor cita que o ataque desse ácaro pode causar a morte de outros hospedeiros dependendo da infestação. Por causar danos severos à planta e por apresentar nível de freqüência de 45,4\%, estando presente em $25 \%$ das coletas (Tabela 1), $T$. Iudeni constitui-se um importante agente a ser estudado visando o controle de $T$. stans.

Além da espécie encontrada, outros ácaros estão registrados para o amarelinho, incluindo três espécies de Tetranychus: (T. urticae Koch; $T$. neocaledonicus André e $T$. desertorum Banks) (Bolland et al., 1998) e o ácaro-branco Polyphagotarsonemus latus Banks (Acari: Tarsonemidae) (Flechtmann et al., 1999).

Observou-se que o número de adultos de

$T$. Iudeni apresentou grandes oscilações ao longo do período estudado, com pico populacional no fim do mês de janeiro (média de 35 adultos por amostra) (Figura 3), e períodos de redução em novembro/dezembro e julho/agosto. É provável que parte destas oscilações sejam reflexo do procedimento de amostragem utilizado, onde apenas 10 plantas, tomadas ao acaso e geralmente diferentes em cada data, foram inspecionadas por completo. A isto contribuiria o fato da distribuição do ácaro ser pouco uniforme entre as plantas, levando à necessidade de se utilizar um maior número de amostras, com a possível troca da unidade amostral de planta para folha. Esta a ser escolhida com base em estudo da distribuição dos ácaros na planta. 
SIMÕES, H.C. et al. Insetos e ácaros associados ao amarelinho..

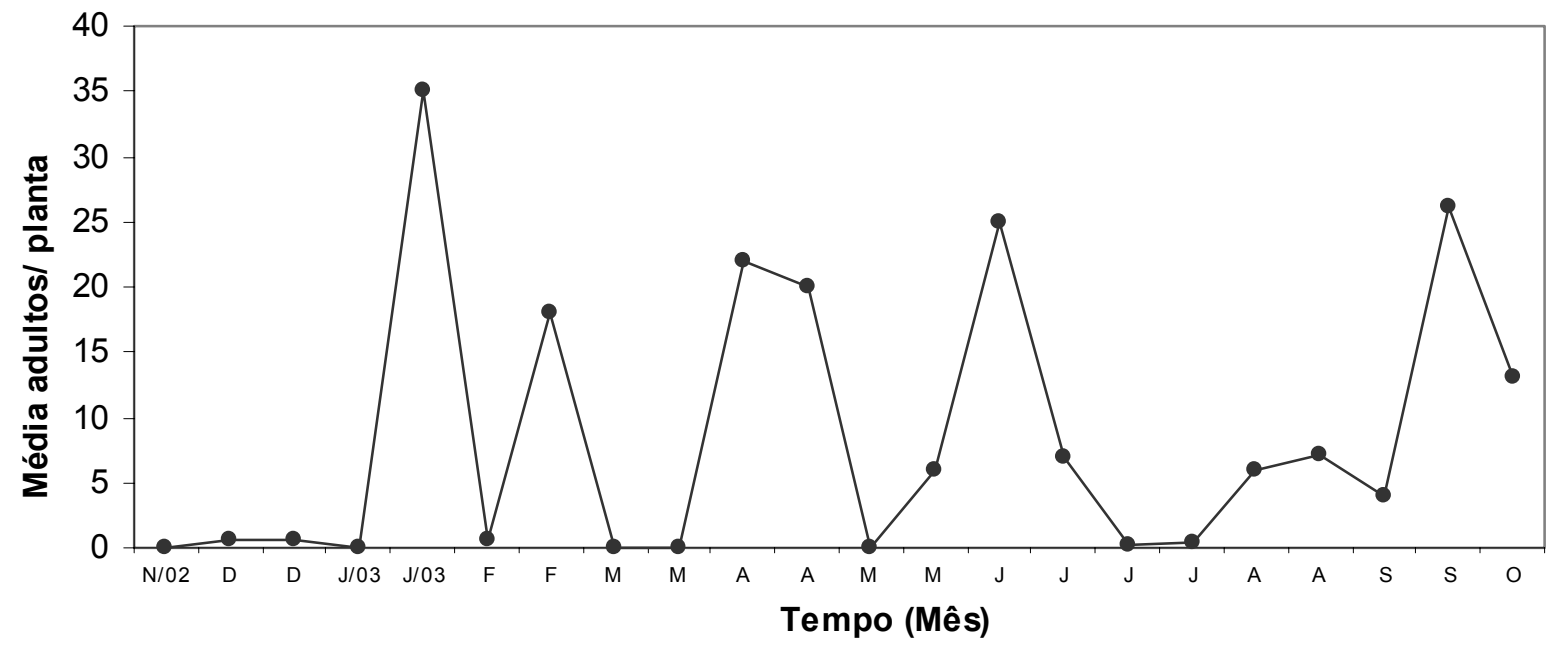

FIGURA 3 - Flutuação populacional do ácaro T. ludeni, coletado quinzenalmente pelo método de inspeção visual em T. stans, no período de novembro/ 2002 a outubro/ 2003. Londrina-PR.

Lagartas de Eulepte sp., coletadas no campo e mantidas em laboratório para a obtenção de adultos, permitiram verificar a ocorrência de uma série de parasitóides, presentes nas coletas de dezembro a junho, com maiores índices de parasitismo na segunda quinzena do mês de março, chegando a $45 \%$ das lagartas coletadas (Figura 2). Os parasitóides em maiores quantidades coletadas pertenceram à família Braconidae, sendo duas espécies de Microgastrinae, e uma espécie de
Cheloninae (Chelonus sp.) (Figura 4). Essa última destaca-se por representar $81,8 \%$ do total de parasitismo. Porém, foi verificada a ocorrência comum de um hiperparasita da família Perilampidae, atuando sobre este braconídeo, com índices superiores a $50 \%$ de parasitismo (Figura 4). Desta forma, é possível que o parasitismo não atinja níveis capazes de inviabilizar a manutenção da população de lagartas de Eulepte sp. no campo.

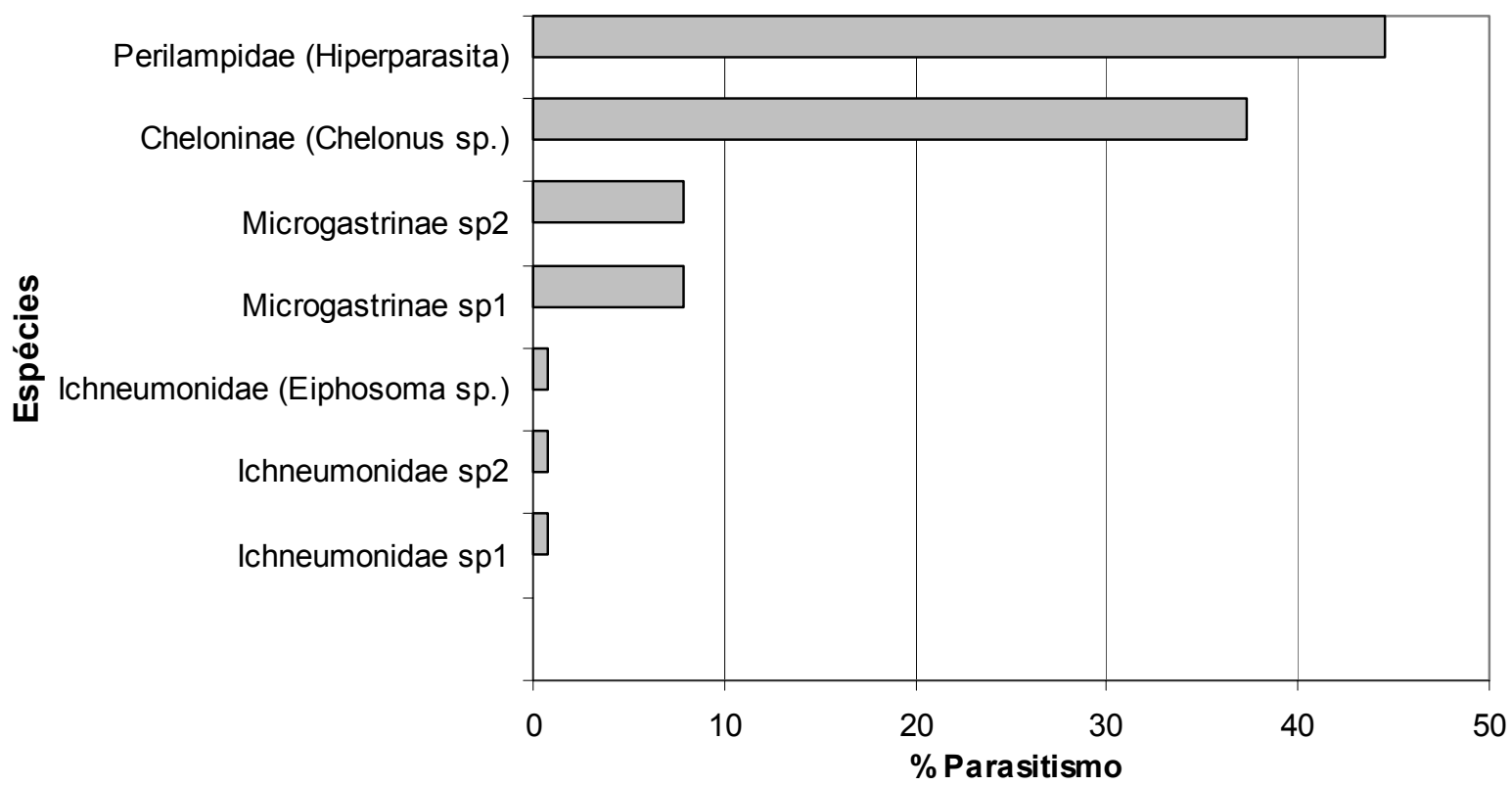

FIGURA 4 - Parasitóides (Hymenoptera) e porcentagem de parasitismo de lagartas de Eulepte sp. coletadas pelo método de inspeção visual, no período de novembro/ 2002 a outubro/ 2003. Londrina-PR.

$\mathrm{Na}$ Colômbia, o braconídeo Chelonus sp. também foi coletado em plantas de $T$. stans, além de uma espécie de Eulophidae e vários ichneumonídeos (Lee et al., 2000). Segundo Hernández \& Briceño (1998), várias espécies da família Braconidae foram observadas parasitando lagartas e ovos de E. gastralis em trabalho realizado na Venezuela. Tais autores citam, ainda, a ocorrência de predadores e patógenos, como o fungo Beauveria bassiana (Bals) e a bactéria Bacillus thuringiensis (Berliner), ambos causando mortalidade das fases imaturas das lagartas. 
SIMÕES, H.C. et al. Insetos e ácaros associados ao amarelinho...

Quanto à influência das variáveis climáticas na ocorrência das espécies potenciais agentes de controle biológico de $T$. stans, pode-se dizer que a flutuação populacional de Eulepte sp. apresentou correlação significativa positiva com as oscilações das temperaturas máxima, mínima e média, apresentando os coeficientes de correlação $0,4976, \quad 0,4774$ e 0,4525 respectivamente, constituindo um fator climático de importância na ocorrência desse inseto. $O$ coeficiente de correlação obtido na análise entre esse fator climático e o número de lagartas demonstrou que, à medida que aumentou a temperatura, houve um acréscimo no número de lagartas encontradas. A precipitação medida durante os 15 dias antecedentes às coletas não apresentou correlação com a variação da população de Eulepte sp., apresentando o valor negativo 0,0588 .

As oscilações na ocorrência de $T$. ludeni não apresentaram correlação significativa com nenhuma das variáveis climáticas testadas.

\section{CONCLUSÕES}

1. Há uma grande diversidade de espécies de artrópodes associados a $T$. stans no município de Londrina - PR.

2. Dentre os artrópodes fitófagos, destacam-se como possíveis agentes de controle biológico de $T$. stans a lagarta-enroladeira Eulepte sp. (Lepidoptera: Pyralidae) e o ácaro-vermelho Tetranychus ludeni (Acari: Tetranychidae).

3. Lagartas de Eulepte sp. são hopedeiras de uma série de parasitóides, destacando-se Chelonus sp. (Hymenoptera: Braconidae) e uma espécie hiperparasita de Chelonus sp pertencente à família Perilampidae.

4. A flutuação populacional de lagartas de Eulepte sp. correlacionou-se positivamente com as oscilações médias de temperatura.

5. A flutuação populacional de T. ludeni não teve correlações significativas com as variáveis climáticas temperatura e precipitação.

\section{REFERÊNCIAS}

1. BOLLAND, H. R., GUTIERREZ, H. R. B. J.; FLECHTMANN, C. H. W. World catalogue of the spider mite family (acari: Tetranychidae). Boston: Brill, 1998. 392 p.

2. BORROR, D. J.; DELONG, D. M. Introdução ao estudo dos insetos. São Paulo: Edgard Blücher, 1969. 653 p.

3. DUTRA, J. C. S.; MACHADO, V. L. L. Entomofauna visitante de Stenolobium stans (Juss.) Seem (Bignoniaceae), durante seu período de floração. Neotropical Entomology, v. 30, n. 1, p. 43-53, 2001.

4. FLECHTMANN, C. H. W. et al. Plant mites (Acari) of the French Antilles. 2. Tarsonemidae and Tydeidae (Prostigmata). Acarologia, v. 40, n. 2, p. 145-146, 1999.

5. GONÇALVES, P. A. S. Levantamento de insetos associados à batata-doce, Ipomoea batatas, com uso de armadilhas d'ágna, em Ituporanga, SC. Anais da Sociedade Entomológica do Brasil, v. 26, n. 1, p. 199-203, 1997.

6. HERNANDEZ, F. R.; BRICEÑO, A. V. Ciclo de vida del gusano esqueletizador Eulepte gastralis (GN.) (Lepidoptera Pyralidae), del apamate (Tabebuia rosea (Bertol.), DC.). Revista Forestal Venezolana, v. 43, n. 1, p. 43-52, 1999.

7. HOLM, L. et al. A geographical atlas of world weeds. New York: John Wiley \& Sons, 1979. $623 \mathrm{p}$

8. JEPPSON, L. R.; KEIFER, H. H.; BAKER, E. W. Injurious tetranychid mites. In: economic plants. Los Angeles: University of California Press, 1975. p. 127-252.

9. JOLY, A. B. Botânica: Introdução à taxonomia vegetal. 3. ed. São Paulo: Nacional, 1976. 598 p

10. JULIEN, M. H.; GRIFFITHS, M. W. Biological contol of weeds: a world catalogue of agents and their target weeds. 4. ed. Queensland: CAB International, 1999. 223 p.

11. KRANZ, W. M.; PASSINI, T. Amarelinho: biologia e controle. Londrina: Instituto Agronômico do Paraná, 1987.19 p. (Informe da Pesquisa, 121).

12. LEE, R. A.; CURE, J. R.; PÉREZ, M. M. Biodiversidad y abundancia relativa de insectos y ácaros en árboles utilizados como cercas vivas en la Sabana de Bogotá. Revista Colombiana de Entomología, v. 26, n. 1-2, p. 1-15, 2000.

13. MARUCCI, R. C.; CAVICHIOLI, R. R.; ZUCCHI, R. A. Chave para as espécies de cigarrinhas (Hemíptera: Cicadellidae: Cicadellinae) vetoras da clorose variegada dos citros (CVC). Anais da Sociedade Entomológica do Brasil, v. 28, n. 3, p. 439-446, 1999.

14. MELLO, J. C. Bignoniaceas Paulistanas. Arquivos do museu paranaense, v. 9, p. 3-206, 1952.

15. MORTON, J. F. Atlas of medicinal plants of middle America: Bahamas to Yucatan. Springfield: C. C. Thomas, 1981. $1420 \mathrm{p}$.

16. PASSINI, T.; KRANZ, W. M. Eficácia de herbicidas no controle de amarelinho (Tecoma stans) em pastagem. Planta Daninha, v. 15, n. 2, p. 190-197, 1997.

17. RENÓ; L. R. Anatomia da raiz e fenologia de Tecoma stans (L.) KUNTH (Bignoniaceae). Maringá: 2002.36 p. (Mestrado em Agronomia) - Programa de Pós Graduação, Departamento de Agronomia, Universidade Estadual de Maringá, Maringá, 2002.

18. SAS. The SAS system for Windows: release 7.0. Cary: SAS Institute Inc., 1998.

19. SCHULTZ, A. R. Introdução ao estudo da botânica sistemática. II vol. 3. ed. Porto Alegre: Globo, 1963. 288 p.

20. SILVA, A. G. et al. Quarto catálogo dos insetos que vivem nas plantas do Brasil: seus parasitos e predadores. Rio de Janeiro: Ministério da Agricultura, Laboratório Central de Patologia, 1968. Parte II. 622 p.

21. SILVEIRA NETO, S.; NAKANO, O.; BARBIN, D. Manual de ecologia de insetos. São Paulo: Agronômica Ceres, 1976. $419 \mathrm{p}$.

22. SOUTHWOOD, T. R. E. Ecological methods. London: Chapman and Hall, 1966. 391 p.

23. YAMAMOTO, P. T.; GRAVENA, S. Espécies e abundância de cigarrinhas e psilídeos (Homoptera) em pomares cítricos. Anais da Sociedade Entomológica do Brasil, v. 29, n. 1, p. 169-176, 2000.

Recebido em 23/01/2008 Aceito em 29/03/2009 
